\title{
Editorial
}

\section{Sustainable and Environmental Catalysis}

\author{
Tommaso Tabanelli ${ }^{1, *(\mathbb{D})}$, Daniele Cespi ${ }^{2, *} *$ (D) and Raffaele Cucciniello ${ }^{3, *}$ (i) \\ 1 Dipartimento di Chimica Industriale “Toso Montanari”, Università di Bologna, Viale del Risorgimento 4, \\ 40136 Bologna, Italy \\ 2 NIER Ingegneria SpA, Via C. Bonazzi 2-40013-Castel Maggiore, 40013 Bologna, Italy \\ 3 Department of Chemistry and Biology, "Adolfo Zambelli" Università di Salerno, Via Giovanni 6 Paolo II, 132, \\ 84084 Fisciano, Italy \\ * Correspondence: tommaso.tabanelli@unibo.it (T.T.); d.cespi@nier.it (D.C.); rcucciniello@unisa.it (R.C.)
}

check for

updates

Citation: Tabanelli, T.; Cespi, D.; Cucciniello, R. Sustainable and Environmental Catalysis. Catalysts 2021, 11, 225. https://doi.org/ $10.3390 /$ catal11020225

Academic Editor:

Jean-François Lamonier

Received: 1 February 2021

Accepted: 3 February 2021

Published: 9 February 2021

Publisher's Note: MDPI stays neutral with regard to jurisdictional claims in published maps and institutional affiliations.

Copyright: (c) 2021 by the authors. Licensee MDPI, Basel, Switzerland. This article is an open access article distributed under the terms and conditions of the Creative Commons Attribution (CC BY) license (https:// creativecommons.org/licenses/by/ $4.0 /)$.

\section{Introduction}

Over the last few decades, an increasing amount of interest from academia and industry has been devoted to the application of the Twelve Principles of the Green Chemistry in order to pursue the Sustainable Development Goals (SDGs) recommended by the United Nations [1]. They are based on the fundamental idea of guiding research and innovation toward more environmental-friendly practices as well as socioeconomic sustainable solutions. Among them, catalysis plays a pivotal role able to address some important needs: (i) avoiding the use of stoichiometric amount of chemicals; (ii) increasing selectivity (i.e., decreasing the generation of waste), and (iii) decreasing energy demand. In this context, with the aim to eliminate environmental pollutants $\left(\mathrm{NO}_{\mathrm{x}}, \mathrm{CO}, \mathrm{SO}_{\mathrm{x}}, \mathrm{VOCs}\right)$ and to design new catalytic routes for clean energy production, environmental and sustainable catalysis represents a noble and one of the most investigated research directions. Moreover, as recently suggested, sustainable and environmental catalysis allows for converting waste in value-added products, and the degradation of pollutants through catalytic combustion/photocatalysis are considered main topics in this context [2,3]. As a matter of fact, it is worth highlighting some recent research advances. The oxidation of chlorinated compounds by catalytic combustion on non-noble metals based oxides [4,5], $\mathrm{NO}_{\mathrm{x}}$ reduction to nitrogen or by selective catalytic reduction (SCR) with ammonia in the presence of heterogeneous catalysts [6]; biofuel production from vegetable oils [7]; the development of new active catalysts for Fenton and photo-Fenton processes [8]; the development of supported nanoparticle catalysts for the treatment of the emission of harmful substances from automobiles, and the use of waste as source of metals for catalysts preparation [9]; the design of new active catalytic systems for the preparation of olefins from polyols [10]; the catalytic hydrotreatment in the valorization of bio-oils obtained from lignocellulosic biomass pyrolysis [11]; and the design of active catalysts for the preparation of organic carbonates from $\mathrm{CO}_{2}$ or bio-based compounds are some examples in this framework [12,13].

This Special Issue aims to cover new and promising examples of sustainable and environmental catalysis with particular emphasis on the adoption of green chemistry principles at both a laboratory and industrial scale.

\section{The Contents of the Special Issue}

In this Special Issue, several fields of research on the sustainable catalytic valorization of biomasses are discussed. Therefore, we would like to sincerely thank all the authors who contributed with their excellent contributions to this Special Issue, which includes fourteen articles.

Cucciniello et al. investigated the use of iron-doped mayenite catalysts for trichloroethylene (TCE) oxidation in the gas phase. All the synthesized catalysts showed good performances for TCE oxidation, totally converted into $\mathrm{CO}_{2}, \mathrm{CO}$, and $\mathrm{HCl}$. Mayenite loaded with $2 \%$ iron was found to be the best catalyst in terms of $\mathrm{T}_{50}\left(300^{\circ} \mathrm{C}\right)$. This result was correlated 
with an optimum combination of the oxidative properties of the mayenite active support with the redox properties of iron, as Temperature Programmed Reduction (TPR), X-ray photoelectron spectroscopy (XPS) and Raman results have shown [14].

Chevez Rivas et al. reported the preparation and characterization of natural purified mordenite treated with a hydrothermal ion exchange process in an acid medium with $\mathrm{Fe}^{2+}$ or $\mathrm{Fe}^{3+}$ salts. The set of samples was characterized regarding their textural properties, morphology, and crystallinity, and tested in the $\mathrm{NO}$ reduction with $\mathrm{CO} / \mathrm{C}_{3} \mathrm{H}_{6}$. The activity in hydrocarbons-selective catalytic reduction (HC-SCR) (used as a reaction test) was found to depend on the ion exchange process [15].

Husnain et al. discussed the selective catalytic reduction of $\mathrm{NO}$ with $\mathrm{NH}_{3}$ at low temperatures with natural iron ore catalysts. The results showed that the sample based on $\alpha-\mathrm{Fe}_{2} \mathrm{O}_{3}$ and $\gamma-\mathrm{Fe}_{2} \mathrm{O}_{3}$ calcined at $250{ }^{\circ} \mathrm{C}$, achieved excellent selective catalytic reduction (SCR) activity (above $80 \%$ at $170-350{ }^{\circ} \mathrm{C}$ ) and $\mathrm{N}_{2}$ selectivity (above $90 \%$, up to $250{ }^{\circ} \mathrm{C}$ ) at low temperatures [16].

Ngoie et al. investigated the potential of a heterogeneous catalyst produced from mineral processing waste for biodiesel production. Tailings from the concentration of cupriferous minerals served as the starting material for synthesis of the catalyst. The nanomagnetic catalysts were prepared using coprecipitation and sol-gel methods, combined with zero-valent iron nanoparticles to form a hydride catalyst. Catalyst properties were assessed using SEM, TEM, BET, and EDX. The maximum yield obtained with this catalyst was $88 \%$ and an average of $27 \%$ decrease in biodiesel yield observed after four reaction cycles [17].

Muhammad Habib et al. discussed the preparation of two alternative catalysts $\left(\mathrm{Co}_{3} \mathrm{O}_{4} / \mathrm{TiO}_{2}\right.$ and 8 wt. $\left.\% \mathrm{ZrO}_{2}-\mathrm{Co}_{3} \mathrm{O}_{4} / \mathrm{TiO}_{2}\right)$ for $\mathrm{CO}, \mathrm{HC}$, and $\mathrm{NO}_{\mathrm{x}}$ conversions. These systems were produced along with a wire mesh-based substrate and tested by mounting them at the exhaust tailpipe of a motorcycle engine. Zirconia-promoted catalyst showed more promising towards $\mathrm{NO}_{x}$ conversion. The cobalt supported by the titania $\mathrm{Co}_{3} \mathrm{O}_{4} / \mathrm{TiO}_{2}$ catalyst showed a performance towards conversion of carbon monoxide, nitrogen oxides, and unburnt hydrocarbons to values of $78.1 \%, 61.9 \%$, and $82.6 \%$ efficiency, respectively, at $1500 \mathrm{RPM}$; whereas, the conversion efficiency of zirconia promoted $\mathrm{ZrO}_{2}-\mathrm{Co}_{3} \mathrm{O}_{4} / \mathrm{TiO}_{2}$ catalyst was $81.3 \%, 78.6 \%$, and $55.1 \%$ towards $\mathrm{HCs}, \mathrm{CO}$, and $\mathrm{NO}_{\mathrm{x}}$, respectively, at 1500 $\mathrm{RPM}$ value. Due to small crystalline size, thermal stability, and fouling inhibition, the $\mathrm{ZrO}_{2}$-promoted $\mathrm{Co}_{3} \mathrm{O}_{4} / \mathrm{TiO}_{2}$ catalyst showed better conversion efficiency towards $\mathrm{CO}$ and $\mathrm{NO}_{\mathrm{x}}$. The slightly lower efficiency of zirconia-promoted catalyst towards $\mathrm{HCs}$ is due to the nonavailability of the vacancies of oxygen for oxidation on $\mathrm{Co}_{3} \mathrm{O}_{4}$. Both catalysts showed selectivity towards $\mathrm{CO}, \mathrm{NO}_{\mathrm{x}}$, and $\mathrm{HC}$, and had comparable performance with respect to the activity of a conventional catalyst [18].

Zhou et al. proposed a copper-based Fenton-like catalyst $\left(\mathrm{Cu} / \mathrm{Al}_{2} \mathrm{O}_{3} / \mathrm{g}-\mathrm{C}_{3} \mathrm{~N}_{4}\right)$ to achieve high degradation efficiencies for Rhodamine $\mathrm{B}(\mathrm{Rh} B)$ in a wide range of $\mathrm{pH}$ (4.9-11.0). The $\mathrm{Cu} / \mathrm{Al}_{2} \mathrm{O}_{3}$ composite was first prepared via a hydrothermal method followed by a calcination process. The composite was then stabilized on graphitic carbon nitride $\left(\mathrm{g}-\mathrm{C}_{3} \mathrm{~N}_{4}\right)$. The characterizations show that $\mathrm{Cu}$ species were immobilized on the $\mathrm{Al}_{2} \mathrm{O}_{3}$ framework in the form of $\mathrm{Cu}^{2+}$ and $\mathrm{Cu}^{+}$, and the introduction of $\mathrm{CN}$ increased its specific surface area and adsorption capacity for $\mathrm{Rh} \mathrm{B}$. The $\mathrm{Cu} / \mathrm{Al}_{2} \mathrm{O}_{3} / \mathrm{CN}$ composite showed an excellent catalytic performance in a wide range of $\mathrm{pH}(4.9-11.0)$. The specific reaction rate constant of Rh B degradation was calculated as $(5.9 \pm 0.07) \times 10^{-9} \mathrm{~m} \cdot \mathrm{s}^{-1}$, and the activation energy was calculated to be $71.0 \mathrm{~kJ} / \mathrm{mol}$. The recycling experiment demonstrated its durability for $\mathrm{Rh} B$ removal and proved that the degradation reaction was surface dominated, with a negligible leaching of copper species in solution [19].

A novel method for preparing highly efficient glass fiber-supported Pt nanoparticle catalysts for the treatment of the emission of harmful substances from automobiles was proposed by Sasaki et al. The Pt catalyst was prepared by depositing a reactive chemically adsorbed monomolecular film with a thiol group at the molecular terminal on the surface of a hydrophilized glass fiber. The monomolecular film enabled the uniform and dense 
grafting of Pt nanoparticles on the surface of the glass fiber as a single layer. Both catalysts exhibited catalytic performance at temperatures $\geq 200^{\circ} \mathrm{C}$. At $300^{\circ} \mathrm{C}$, the octane combustion rates (index for evaluating performances of the $\mathrm{Pt}$ and commercially available catalysts) of the catalysts were $\geq 80 \%$. At $50-400{ }^{\circ} \mathrm{C}$, the octane combustion rates of both catalysts were approximately the same. Pt catalysts were found to exhibit catalytic performance comparable to that of Pd catalysts under lean conditions, despite the lower price [20].

Research conducted by Villamarin-Barriga et al. showed that the residual sludge of galvanic industries can be used as catalytic materials (after thermal treatment) for the synthesis of materials. Researchers evaluated the sludge from three galvanic industries. Catalyst was obtained from a thermal process based on sludge dried between 100 and $120^{\circ} \mathrm{C}$, and calcination of sludges between 400 to $700{ }^{\circ} \mathrm{C}$. Catalytic activity was analyzed by thermogravimetric analysis of a thermocatalytic decomposition of crude oil. The best conditions for catalyst synthesis were calcination between 400 and $500{ }^{\circ} \mathrm{C}$, the temperature of reduction between 750 and $850^{\circ} \mathrm{C}$ for $15 \mathrm{~min}$. The catalytic material had mainly Fe as active phase and a specific surface between $17.68-96.15 \mathrm{~m}^{2} \cdot \mathrm{g}^{-1}$; the catalysts promoted around $6 \%$ more weight-loss of crude oil in the thermal decomposition compared with assays without the catalyst. To determinate the environmental sustainability of this process, the E-factor (mass of waste/mass of product) was calculated by obtaining values between 0.1 and 0.3 ; the ideal E-factor is zero [21].

In the manuscript of Klein Gebbink et al., two new tetradentate $\mathrm{N}$-donor ligandsupported $\mathrm{ReO}_{2}{ }^{+}$complexes (cis-[(BPMEN)ReO $\left.\mathrm{R}_{2}\right] \mathrm{PF}_{6}$ and cis-[(BmdmPMEN) $\left.\mathrm{ReO}_{2}\right] \mathrm{PF}_{6}$ ) were synthesized and fully characterized. They were found to be active in deoxydehydration $(\mathrm{DODH})$ reactions of diols, suggesting that $\operatorname{Re}(\mathrm{V})$ dioxo complexes can be involved in DODH catalysis. Treatment of $\left(\mathrm{N}_{2} \mathrm{Py}_{2}\right) \mathrm{ReO}_{2}{ }^{+}$with an excess amount of water generates an active species for DODH catalysis; use of the Re-product of this reaction shows a much shorter induction period compared to the pristine complex. No ligand is coordinated to the "water-treated" complex, indicating that the real catalyst is formed after ligand dissociation. IR analysis suggested this catalyst to be a rhenium-oxide/hydroxide oligomer. The monodentate pyridine ligand is much easier to dissociate from the metal center than a tetradentate $\mathrm{N}_{2} \mathrm{Py}_{2}$ ligand, which makes the $\mathrm{Py}_{4} \mathrm{ReO}_{2}{ }^{+}$-initiated DODH reaction more efficient. For the $\mathrm{Py}_{4} \mathrm{ReO}_{2}{ }^{+}$-initiated DODH of diols and biomass-based polyols, both $\mathrm{PPh}_{3}$ and 3-pentanol could be used as a reductant. Excellent olefin yields are achieved [22].

The manuscript of Ray et al. reports on the photocatalytic and antibacterial activity of $\mathrm{ZnO}$ nanoparticles. This activity is strongly related to the amount of surficial reactive oxygen species (ROS) and metal ions $\left(\mathrm{Zn}^{2+}\right)$ which, in turn, is strictly dependent on the morphology of the nanomaterials. In this context, the authors managed to optimize the preparation of different $\mathrm{ZnO}$ nanospheres, nanopetals, and nanorods by varying the precipitation solvent ranging from PEG400, water, and toluene. These nanocatalysts (dimension ranging from 10 to few hundreds nanometers) were effective in killing $99 \%$ of bacteria at low concentrations in water while the photodegradation of caffeine using solar light was completed after 120 min using the optimized $\mathrm{ZnO}$ nanospheres. These results are promising; therefore, the mechanism of both the processes will be investigated in depth in future investigations [23].

The research work of Kaewkannetra and coworkers show the possibility to successfully valorize the triglyceride-rich palm-oil mill effluent (POME) through the combination of biological and thermochemical processes. In this complementary approach, the aqueous waste of the palm oil manufacture first undergoes an enzymatic hydrolysis with yield up to $90 \%$ in free fatty acids (FFA). Subsequently, FFA are efficiently converted into long chain hydrocarbon mixtures, suitable for jet fuel application, via the heterogeneously catalyzed hydrogenation reaction $\left(\mathrm{Pd} / \mathrm{Al}_{2} \mathrm{O}_{3}, 400^{\circ} \mathrm{C}, 10\right.$ bar of $\left.\mathrm{H}_{2}, 1 \mathrm{~h}\right)$. This innovative and complementary approach for the valorization of $\mathrm{POME}$ was never reported in literature and represents a new way to both alleviate the wastewater environmental issue and to obtain a high value-added product (jet fuels) for local biorefineries (e.g., Southeast Asia) [24]. 
Dutta et al. reported on the catalytic activity of $\mathrm{Pd} / \mathrm{SiO}_{2}$ for the selective oxidation of $\mathrm{CO}$ at low temperature. An extensive characterization of the catalytic materials (by FTIR, TGA-DSC, TEM, and XPS) allowed for investigating the influence of the thermal pretreatment on catalyst activity and stability. Interestingly, a structure-activity relationship was proposed, correlating the catalyst activation and $\mathrm{CO}$ oxidation hysteresis behavior with the information on both the palladium oxidation states and nanoparticle dispersion. In particular, the best low-temperature $\mathrm{CO}$ oxidation performance was achieved by calcining the catalyst at $450{ }^{\circ} \mathrm{C}[25]$.

In a comprehensive review, Paone et al. extensively discussed the potentials of catalytic hydrotreatment in the valorization of bio-oils obtained from either lignocellulosic biomass pyrolysis or by the physical pressing of oleaginous vegetable seeds. This treatment uses high-pressure hydrogen in order to both stabilize the bio-oil and decrease the amount of oxygenated compounds, in this way obtaining mixtures suitable for direct use as dropin biofuels. In particular, the current state-of-the-art on the reaction pathways, catalyst formulations, and reactor technology (i.e., traditional vs. membrane) were analyzed indepth [26].

Zhang et al. proposed an innovative series of binuclear aluminum complexes as highly active and selective homogeneous catalysts for the cycloaddition reaction of epoxides and carbon dioxide. The reaction is of interest because the market for organic carbonates is steadily increasing due to their utilization as solvents, electrolytes, and monomers for high-performance polymers (i.e., polycarbonates, polyurethane, and polyureas), as well as a way to valorize $\mathrm{CO}_{2}$ as a feedstock. Interestingly, the bifunctional tridentate tetrammino phenoxyimino-phenoxy aluminum complex is also active in very mild conditions, i.e., $100{ }^{\circ} \mathrm{C}$ and low $\mathrm{CO}_{2}$ pressure ( $\leq 2 \mathrm{~atm}$ ), which allows for obtaining good to excellent conversions of the parental epoxides. Kinetic investigations showed a first-order dependence on the concentration of the epoxide for the target reaction [27].

Funding: This research received no external funding.

Conflicts of Interest: The authors declare no conflict of interest.

\section{References}

1. Cespi, D.; Esposito, I.; Cucciniello, R.; Anastas, P.T. Beyond the beaker: Benign by design society. Curr. Res. Green Sustain. Chem. 2020, 3, 100028. [CrossRef]

2. Fasolini, A.; Cespi, D.; Tabanelli, T.; Cucciniello, R.; Cavani, F. Hydrogen from Renewables: A Case Study of Glycerol Reforming. Catalysts 2019, 9, 722. [CrossRef]

3. Bellè, A.; Tabanelli, T.; Fiorani, G.; Perosa, A.; Cavani, F.; Selva, M. A Multiphase Protocol for Selective Hydrogenation and Reductive Amination of Levulinic Acid with Integrated Catalyst Recovery. ChemSusChem 2019, 12, 3343-3354. [CrossRef]

4. Cucciniello, R.; Intiso, A.; Castiglione, S.; Genga, A.; Proto, A.; Rossi, F. Total oxidation of trichloroethylene over mayenite $\left(\mathrm{Ca}_{12} \mathrm{Al}_{14} \mathrm{O}_{33}\right)$ catalyst. Appl. Catal. B Environ. 2017, 204, 167-172. [CrossRef]

5. Intiso, A.; Martinez-Triguero, J.; Cucciniello, R.; Proto, A.; Palomares, A.E.; Rossi, F. A Novel Synthetic Route to Prepare High Surface. Catalysts 2019, 9, 27. [CrossRef]

6. Chen, Z.; Liu, Q.; Guo, L.; Zhang, S.; Pang, L.; Guo, Y.; Li, T. The promoting mechanism of in situ Zr doping on the hydrothermal stability of Fe-SSZ-13 catalyst for NH3-SCR reaction. Appl. Catal. B Environ. 2021, 286, 119816. [CrossRef]

7. Ricciardi, M.; Falivene, L.; Tabanelli, T.; Proto, A.; Cucciniello, R.; Cavani, F. Bio-Glycidol Conversion to Solketal over Acid Heterogeneous Catalysts: Synthesis and Theoretical Approach. Catalysts 2018, 8, 391. [CrossRef]

8. Prete, P.; Fiorentino, A.; Rizzo, L.; Proto, A.; Cucciniello, R. Review of aminopolycarboxylic acids-based metal complexes application to water and wastewater treatment by (photo-)Fenton process at neutral pH. Curr. Opin. Green Sustain. Chem. 2021. [CrossRef]

9. Cova, C.M.; Zuliani, A.; Manno, R.; Sebastian, V.; Luque, R. Scrap waste automotive converters as efficient catalysts for the continuous-flow hydrogenations of biomass derived chemicals. Green Chem. 2020, 22, 1414-1423. [CrossRef]

10. Scioli, G.; Tonucci, L.; Di Profio, P.; Proto, A.; Cucciniello, R.; D'Alessandro, N. New green route to obtain (bio)-propene through 1,2-propanediol deoxydehydration. Sustain. Chem. Pharm. 2020, 17, 100273. [CrossRef]

11. Kang, S.; Li, X.; Fan, J.; Chang, J. Hydrothermal conversion of lignin: A review. Ren. Sustain. Energy Rev. 2013, $27,546-558$. [CrossRef]

12. Aomchad, V.; Cristofol, A.; Della Monica, F.; Limburg, B.; D’Elia, V.; Kleij, A. Recent progress in the catalytic transformation of carbon dioxide into biosourced organic carbonates. Green Chem. 2021. [CrossRef] 
13. Tabanelli, T.; Giliberti, C.; Mazzoni, R.; Cucciniello, R.; Cavani, F. An innovative synthesis pathway to benzodioxanes: The peculiar reactivity of glycerol carbonate and catechol. Green Chem. 2019, 21, 329. [CrossRef]

14. Cucciniello, R.; Intiso, A.; Siciliano, T.; Palomares, A.P.; Martinez-Triguero, J.; Cerrillo, J.L.; Proto, A.; Rossi, F. Oxidative Degradation of Trichloroethylene over $\mathrm{Fe}_{2} \mathrm{O}_{3}$-doped Mayenite: Chlorine Poisoning Mitigation and Improved Catalytic Performance. Catalysts 2019, 9, 747. [CrossRef]

15. Rivas, F.C.; Rodriguez-Iznaga, I.; Berlier, G.; Ferro, D.T.; Concepcion-Rosabal, B.; Petranovskii, V. Fe Speciation in Iron Modified Natural Zeolites as Sustainable Environmental Catalysts. Catalysts 2019, 9, 866. [CrossRef]

16. Husnain, N.; Wang, E.; Fareed, S. Low-Temperature Selective Catalytic Reduction of $\mathrm{NO}$ with $\mathrm{NH}_{3}$ over Natural Iron Ore Catalyst. Catalysts 2019, 9, 956. [CrossRef]

17. Ngoie, W.I.; Weiz, P.J.; Ikhu-Omoregbe, D.; Oyekola, O.O. Heterogeneous Nanomagnetic Catalyst from Cupriferous Mineral Processing Gangue for the Production of Biodiesel. Catalysts 2019, 9, 1047. [CrossRef]

18. Rehman, M.H.U.; Noor, T.; Iqbal, N. Effect of Zirconia on Hydrothermally Synthesized $\mathrm{Co}_{3} \mathrm{O}_{4} / \mathrm{TiO}_{2}$ Catalyst for $\mathrm{NO}_{\mathbf{x}}$ Reduction from Engine Emissions. Catalysts 2020, 10, 209. [CrossRef]

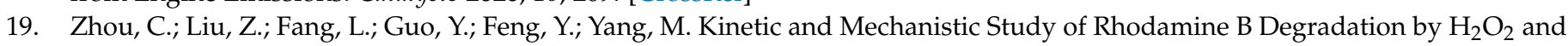
$\mathrm{Cu} / \mathrm{Al}_{2} \mathrm{O}_{3} / \mathrm{g}-\mathrm{C}_{3} \mathrm{~N}_{4}$ Composite. Catalysts 2020, 10, 317. [CrossRef]

20. Sasaki, T.; Horino, Y.; Ohtake, T.; Ogawa, K.; Suzaki, Y. A Highly Efficient Monolayer Pt Nanoparticle Catalyst Prepared on a Glass Fiber Surface. Catalysts 2020, 10, 472. [CrossRef]

21. Villamarin-Barriga, E.; Canacuan, J.; Londono-Larrea, P.; Solis, H.; De La Rosa, A.; Saldarriaga, J.F.; Montero, C. Catalytic Cracking of Heavy Crude Oil over Iron-Based Catalyst Obtained from Galvanic Industry Wastes. Catalysts 2020, 10, 736. [CrossRef]

22. Li, J.; Lutz, M.; Gebbink, R.J.M.K. N-Donor Ligand Supported "ReO ${ }^{2+}$ ": A Pre-Catalyst for the Deoxydehydration of Diols and Polyols. Catalysts 2020, 10, 754. [CrossRef]

23. Thakur, S.; Neogi, S.; Ray, A.K. Morphology-Controlled Synthesis of ZnO Nanostructures for Caffeine Degradation and Escherichia coli Inactivation in Water. Catalysts 2021, 11, 63. [CrossRef]

24. Muanruksa, P.; Winterburn, J.; Kaewkannetra, P. Biojet Fuel Production from Waste of Palm Oil Mill Effluent through Enzymatic Hydrolysis and Decarboxylation. Catalysts 2021, 11, 78. [CrossRef]

25. Al Soubaihi, R.M.; Saoud, K.M.; Myint, M.T.Z.; Gothelid, M.A.; Dutta, J. CO Oxidation Efficiency and Hysteresis Behavior over Mesoporous $\mathrm{Pd} / \mathrm{SiO}_{2}$ Catalyst. Catalysts 2021, 11, 131. [CrossRef]

26. Bagnato, G.; Sanna, A.; Paone, E.; Catizzone, E. Recent Catalytic Advances in Hydrotreatment Processes of Pyrolysis Bio-Oil. Catalysts 2021, 11, 157. [CrossRef]

27. Zhang, Z.; Wang, T.; Xiang, P.; Du, Q.; Han, S. Syntheses, Characterization, and Application of Tridentate Phenoxyimino-Phenoxy Aluminum Complexes for the Coupling of Terminal Epoxide with $\mathrm{CO}_{2}$ : From Binary System to Single Component Catalyst. Catalysts 2021, 11, 145. [CrossRef] 